\title{
A VOICE-BASED E-EXAMINATION FRAMEWORK FOR VISUALLY IMPAIRED STUDENTS IN OPEN AND DISTANCE LEARNING
}

\author{
Dr. Ambrose A. AZETA \\ Department of Computer and Information Sciences \\ Covenant University \\ Ota, Nigeria \\ Itorobong A. INAM \\ Department of Computer and Information Sciences \\ Covenant University \\ Ota, Nigeria \\ Dr. Olawande DARAMOLA \\ Department of Information Technology \\ Cape Peninsula University of Technology \\ Cape Town, South Africa
}

\begin{abstract}
Voice-based systems allow users access to information on the internet over a voice interface. Prior studies on Open and Distance Learning (ODL) e-examination systems that make use of voice interface do not sufficiently exhibit intelligent form of assessment, which diminishes the rigor of examination. The objective of this paper is to improve on the achievements of previous studies by providing a framework that will guide the development of a voice-based eexamination expert system for the visually impaired students in ODL. The study employs a combination of technologies such as system design, server side scripting, voice-based system development, data management and rule-based reasoning in developing the system. The system was evaluated to determine the level of usability. The results of the usability evaluation showed that the developed application has an 'average usability' rating of 3.48 out of 5 scales. The findings show that the voice-based e-examination system will not only be of immense benefit to the visually impaired students in ODL in respective of distance, but will also complement the existing web-based method for online examination.
\end{abstract}

Keywords: Distance learning, e-examination, intelligent, voice and framework.

\section{INTRODUCTION}

The term Open and Distance Learning (ODL) has become very popular in most societies, particularly in educational institutions, as result of its nature that is characterized by learning irrespective of time, distance and location. A previous study by Ayo, Odukoya and Azeta (2014), reports on the potential benefits of adopting ODL in the educational sector, and also emphasized on web as the most prevalent platform for hosting ODL applications. However, the normal web is not as usable and accessible for people with vision impairments, as it is for able-bodied sighted people (Puzis, Borodin, Puzis and Ramakrisnan, 2013). Studies on the level of availability of distance learning show that web-based learning does not completely respond to the requirements of the visually impaired persons (Liakou and Manousou, 2015). ODL based on assistive technology allows individuals with disabilities to do things that were difficult or impossible for them in the normal learning environment (Alsobhi, Khan and Rahanu, 2015). The ease of access to distance learning programmes by the visually impaired 
is well-defined by the existence of significant learning resources and its usability (Arditi, 2012). ODL based on assistive technology establishes a system appropriate for persons with disabilities and more predominantly, for individuals with visual impairment, as it can add to their incorporation into the educational and societal environment (Liakou and Manousou, 2015).

The National Center for Education Statistics, U.S. Department of Education, Washington DC, is of the opinion that the amount of students with disabilities attending higher institution is on the increase (NCES, 2016). With the rising number of visually impaired people attending tertiary schools, there has been a growing need for assistive technologies that can aid these students. Voice User Interface (SUI) systems are mainly designed for those with visual problems to resolve the issue of web convenience (Azeta, Ayo, Atayero and Ikhu-Omoregbe, 2009). In order to increase the quality of life of the blind and partially sighted persons, special attention needs to be paid to their education (Lucic, Ostrogonac, Sedlar and Selujski, 2015). The application of voice in different fields has achieved an expanding consideration in taking care of different issues using cell phones, and with the advancement in voice technology, text information can be transmitted effortlessly to the user.

One very important tool used for implementing VUI systems is VoiceXML. Voice-based systems use technologies that allow users to traverse through a voice system using a cellular phone and voice instructions (Gallivan, Hong, Jordan and $\mathrm{Li}, 2002$ ). In education, the learning outcome is determined by means of examination. These examinations should be easily available and accessible by all categories of students irrespective of disability. The way examinations are conducted for students with visual impairment is one of a whole range of issues that need to be reconsidered and requires changes and improvements (Papadopoulos, Simaioforidis, Charitakis and Barouti, 2014).

Existing ODL web applications are text-based and graphical in nature and therefore sight is required to navigate these systems. A study in Murphy et al. (2008) analyzed challenges that the visually impaired people have on reading information and navigating the web pages. Murphy et al. (2008), used a multi-modal approach of combining visual and audio technologies to aid the visually impaired to access the internet. Although accessibility was achieved, some level of intelligence would have further enhanced the convenience of navigating the menu driven dialogue sequence for these categories of students, as a result of their disability. Previous studies on e-examination systems that make use of VUI do not sufficiently exhibit an intelligent form of assessment, which diminishes the rigour of examination. At the level of ODL, what mostly exist are internet technologies that support learning and examination for the able-bodied learners. The visually impaired are therefore neglected in the scheme of technology-enhanced learning. Also, it can be challenging to achieve educational and mental assessments for students who are visually impaired using the normal examination system (Willings, 2016). There is, therefore, a need for a voice-based platform to assist these categories of students and hence the motivation for this research.

The focus of this study is to provide a framework for the implementation of intelligent voicebased e-examination system for the blinds in ODL using voice technologies. The application is an online system that embeds expert knowledge-base to provide intelligent component services on the e-examination system platform. The remaining part of this paper is organized as follows: Section two presents related works. Section three describes the system framework and design with dialogue sequence, and algorithm development. Section four highlights the implementation of the system and usability evaluation. Section five concludes the paper. 


\section{RELATED WORKS}

The issue of accessibility using web and voice is very paramount in the sense of ensuing access for the physically challenged in learning and assessment in an ODL environment (Martyn, 2014). Some prior researches in the area of e-examination focused mainly on the web platform, such as in Choudhury, Borbora and Sarma, (2013); Hatzilygeroudis et al, (2005), using internet technologies and voice technologies (Azeta et al., 2009). Other studies on voicebased learning focused on providing auditory interfaces to the visually impaired learners (García, Ruiz and Pérez, 2012). In a study by García, Ruiz and Pérez (2012), interactive classroom software that offers a way for cross-platform access to internet learning was introduced. A voice system was proposed that assembles a complex voice modules and elearning materials. VoiceXML was used to develop the voice dialogues and ASR and Dual Tone Multi Frequency (DTMF) signals were used for input modality.

Raghuraman, (2004) designed, implemented and deployed a voice-based application called VHELP system. In the system, a portion of the Computer Science and Engineering (CSE) department website was voice enabled using VoiceXML tool to enable the visually impaired student population to have access to the departmental information. Motiwalla and Qin, (2007) and Motiwalla, (2009), explored the combination of $\mathrm{m}$-Learning applications and voice recognition technologies to reduce access barriers for normal users and visually/mobility impaired users. The system includes an Interactive Voice Response (IVR) system that enabled learning for blind students from higher educational institution of learning.

In Velonis, Milonas, Papazidis and Dimitriou (2009), VoiceCampus, an IVR system for students of the University of Crete, Greece was developed. With the system, students have access to information and examination results which was always made available on the internet. This gives students ease to information and examination results. In [21] an online test system using a visual agent as an auditor that is voice-based was proposed. A one-way question design test was conducted with three groups in order to study the effects of the usage of the agent in the voice-based system. In Azeta et al. (2008), a prototype telephony portal system for course registration and examination known as (CourseRegExamOnline) was developed. The system offers dual access module using VUI and Web User Interface (WUI). WUI provides registration services and access to examination question management.

A lot more studies have been done by different scholars in an attempt to provide intelligent services in the e-examination for the visually impaired in a normal traditional examination system using voice. For instance, Azeta et al. (2009) developed an intelligent voice-based eLearning system with a multimodal user interface. Case-based Reasoning (CBR) was used as an intelligent component of the system making it possible for the system to reason from experience. The system was used for course registration, voice learning tutorial lectures and examination. The system was designed for normal traditional examination settings where students reside within school campus and stayed in their dormitory.

This study make a contribution to the ODL domain by providing a framework that integrates VoiceXML and expert system for the development of e-examination voice interface in distance learning environment to support the visually impaired students.

\section{RESEARCH DESIGN}

In designing the proposed framework, schematic diagram symbols were engaged. A usability evaluation of the system was carried out using ISO 9241-11, (1998) to measure the effectiveness, efficiency and satisfaction of the system. In carrying out the field survey of users' opinion of the system, questionnaires were distributed to students. The designed 
questionnaire had three sections: Background information of respondents (6 questions), user satisfaction (6 questions), effectiveness (5 questions) and efficiency (6 questions). The questions were administered via a five-point rating scale where $1=$ strongly disagree, $\mathbf{2}=$ disagree, $\mathbf{3}=$ undecided, $\mathbf{4 = a g r e e}$ and $\mathbf{5 = s t r o n g l y ~ a g r e e . ~ A ~ t o t a l ~ o f ~ t e n ~ q u e s t i o n n a i r e s ~ w e r e ~}$ administered and all the responses were received and analyzed. The participants of the usability survey includes university students.

\section{THE PROPOSED FRAMEWORK AND SYSTEM DESIGN}

The proposed voice-based e-Examination framework is presented in Figure 1. It consists of the presentation tier, business logic tier and data tier.

\section{Presentation Tier}

The presentation tier provides users interface for voice and web, and also gives users access to the system using portable and smart devices. The components of the VUI are land and mobile phones. The WUI is made up of PCs and laptop. Users dial into the system using their mobile devices to participate in examination, while the administrator manages the user's profile and uploads examination questions through WUI.

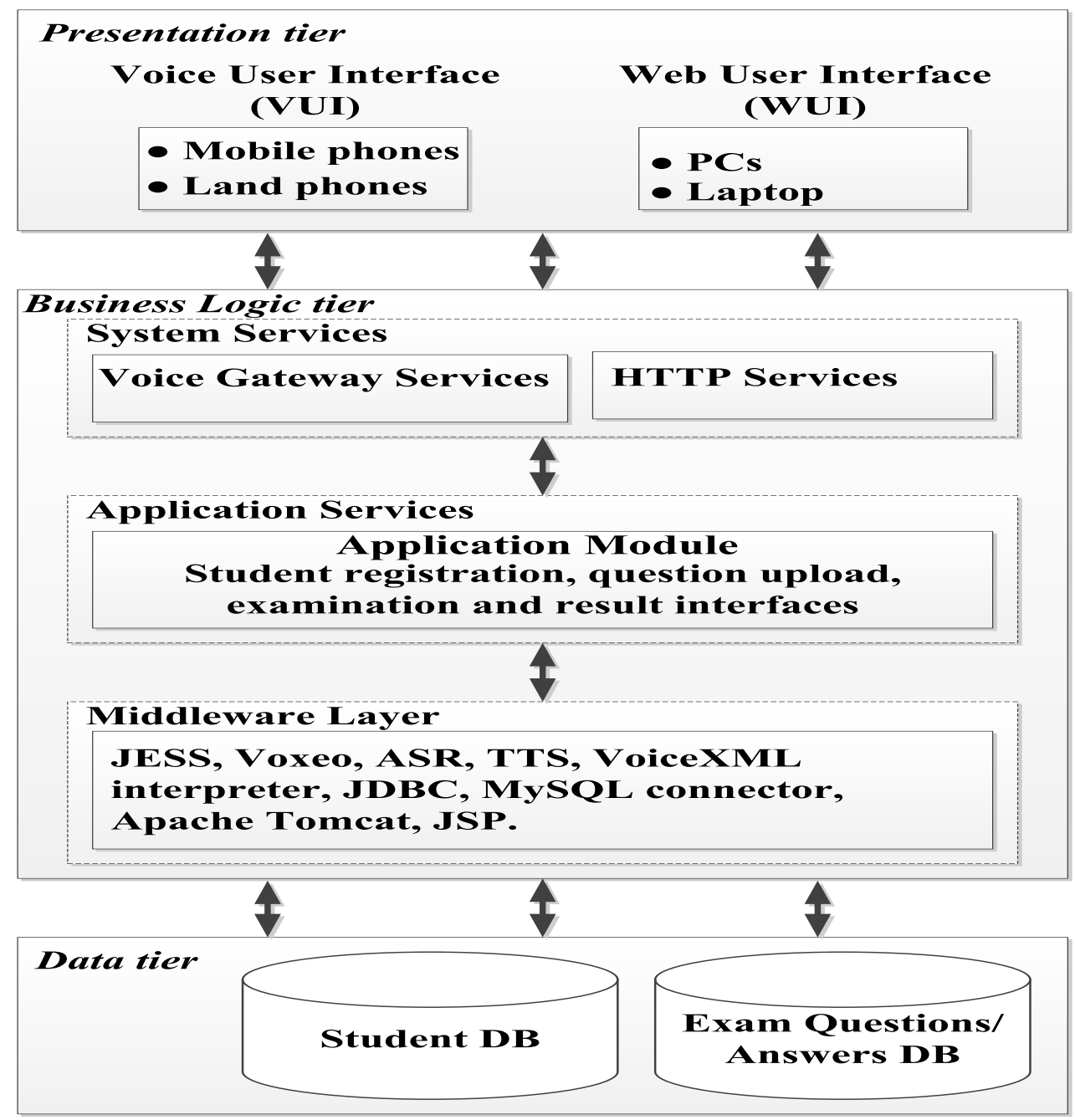

Figure 1. The voice-based e-examination framework 


\section{Business Logic Tier}

The business logic tier separates the presentation tier and the data tier. It consists of the system services, application services and the middleware layer. The system service components are the voice gateway and Hypertext Transmission Protocol (HTTP) services. The application services are made up of all the system's modules such as student registration, question upload, examination and results processing. A user gets access to the application through the VUI using a mobile phone in real-time. The Text-To-Speech (TTS) and Automatic Speech Recognition (ASR) interpreter, which are the middleware tools, are used for the voice translation. The VoiceXML interpreter communicates through the HTTP services to the Voxeo server. The web application uses the apache tomcat to retrieve information from the database and the VoiceXML interpreter TTS sends the response to the caller using voice. The middleware layer comprise of the tools engaged in the system development such as expert system, voice technologies, server side processing and database.

\section{Data Tier}

The data tier provides Database Management System (DBMS) functionalities. The data tier contains information about the students, course, program, questions, answers and results. MySQL was used to implement the database.

\section{Class Structure Model}

The class model for the e-examination system database is shown in Figure 2. Each class has three compartments. The class name, the attribute names and methods (the operations to be carried out on attribute). The lines show association between the classes. The examination taken by students is determined by the courses registered.

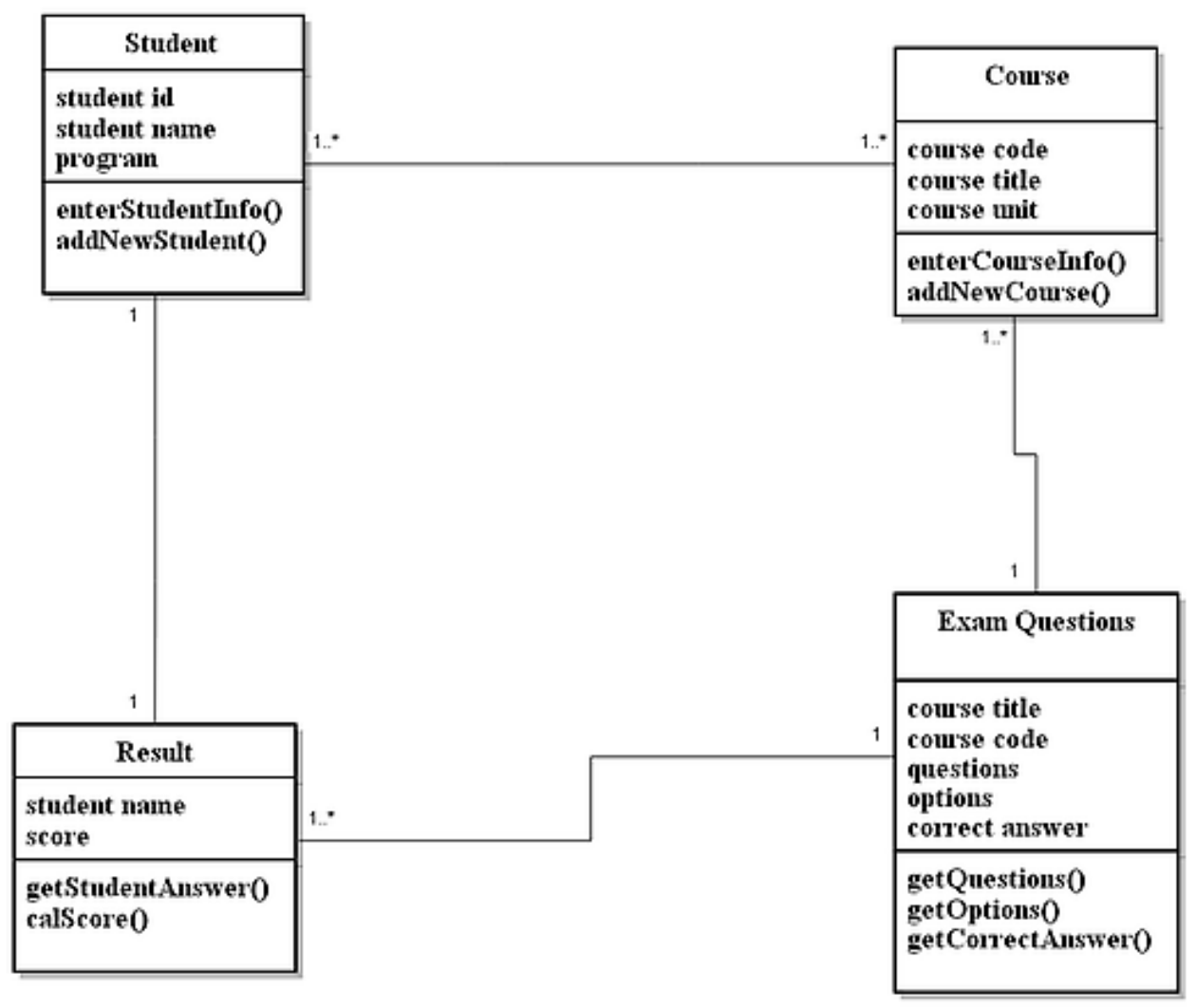

Figure 2. A Class Diagram for the e-Examination System Database 
The Dialogue Sequence

The pseudocode for the dialogue sequence used for the design of the system is shown in Figure 3. When a user dial into the system, the user will have to undergo certain conversation with the system in order to accomplish the desired task. The dialogue sequence shows how the system will be used by the users. It contains a system prompt that says a welcome message to the user, which is followed by sets of menu options in form of conditional statement using IF statement.

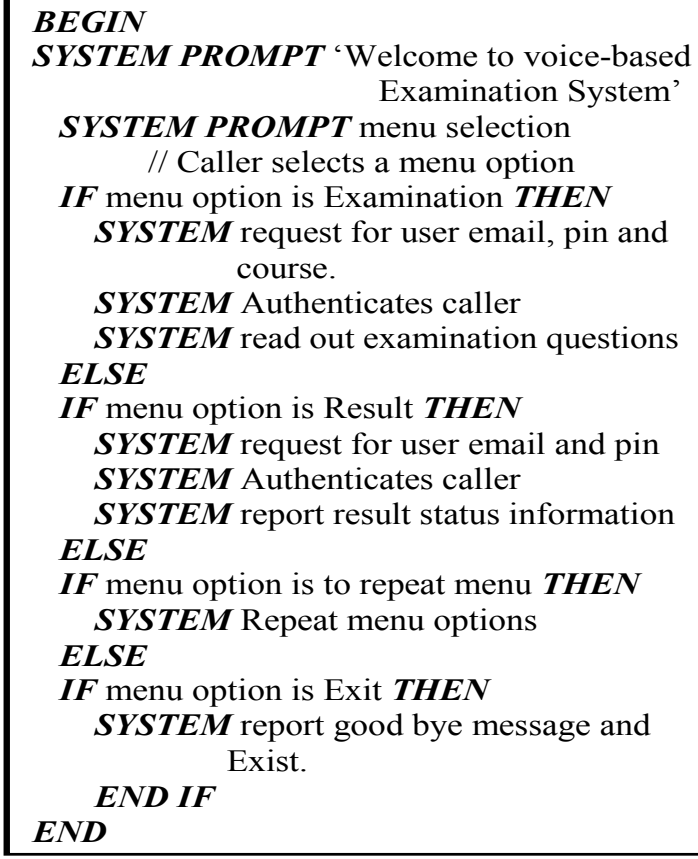

Figure 3. Pseudocode for the Dialogue Sequence

\section{Algorithm development}

In generating the sets of questions, the Fisher-Yates shuffling algorithm in Olu, (2012), was used to activate randomization of examination questions as shown in Figure 3. The algorithm describe a situation whereby a random item is selected and swapped with another item before an array of $\mathbf{N}$ locations is created. This results in generation of random numbers, comparison of generated numbers with previous number in array, leading to generation of examination questions. In the design of the system, the role and interaction of the users were modeled using the Unified Modeling Language (UML) which involves use case diagram, class diagram, activity diagram and sequence diagram.

\section{SYSTEM IMPLEMENTATION AND EVALUATION}

The VUI of the system was implemented using VoiceXML and the speech engine used was Voxeo Prophecy (Voxeo Prophecy, 2003). Java Expert System Shell (JESS) was used for enabling the expert system functionalities. The shuffling algorithm for generating random questions is contained in Figure 4. 


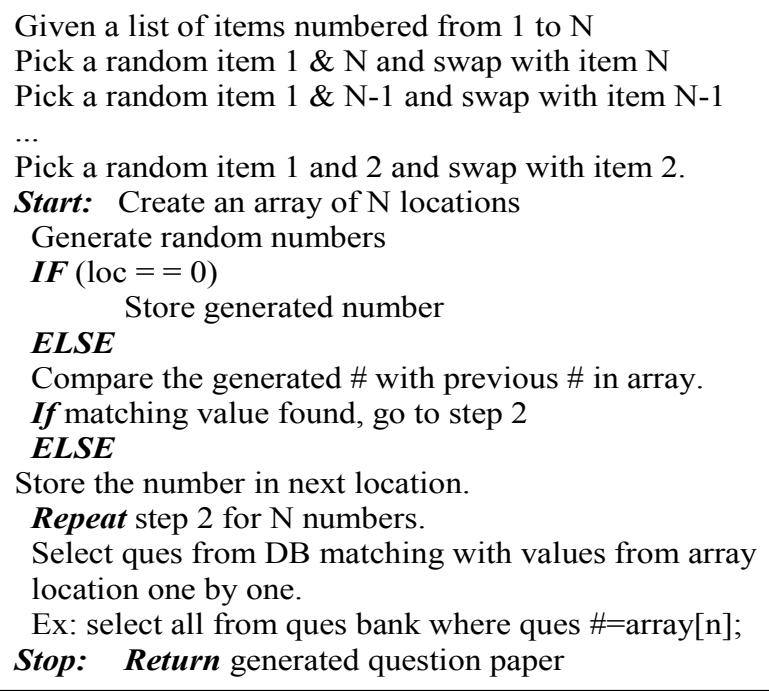

Figure 4. Shuffling algorithm for generating random questions

The system was implemented such that every validated user is presented with a dialog menu and examination questions that will be read out to the user. Users' answers are matched against the right answers in the database and the result communicated to the users through voice. When the application is run on a local computer, the user dial a particular sip number on Voxeo Prophecy (2003), to connect to the e-examination system and thereafter follow the dialogue sequence. When the system is deployed on a Voxeo speech engine, a number that is generated on the Voxeo platform is dialed from a mobile phone to connect to the eexamination system. The VUI gives instant feedback of examination results, as it is with a web-based examination. The WUI was implemented using JSP/Servlets which provides easy access to the expert shell. For the server side, JSP and Apache Tomcat were used, while MySQL and JDBC were used as the database. The WUI includes a login page, examination page, and addition of exam questions page. The sample screen shot in Figure 5 is a display of multiple examination questions and options in radio button list. Users are required to select only one option for each question.

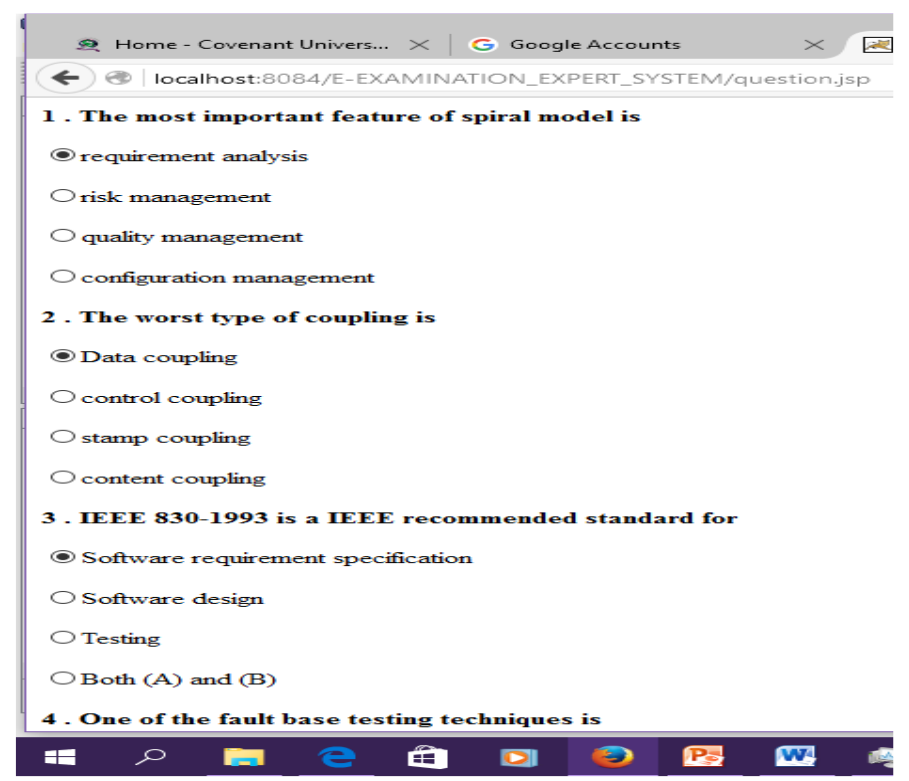

Figure 5. Sample Examination Questions 
Accessing the system

The voice user interface is accessed by calling a cellular phone number while the WUI is available through the web. When starting the dialogue, the system will have to authenticate the student and the course the student wishes to take the examination on. Once the process of authentication is completed, the welcome message and a rundown of menu choices will be presented. The web interface of the system is used by the system administrator for managing students' profile, examination question, course and result. The voice interface of the system can be accessed by users while the web interface can only be accessed by the administrator.

Voxeo Prophecy voice server was installed on a local computer and used to test the voice interface of the system (see Figure 6). Dialing a SIP phone number from the Voxeo Prophecy SIP phone connects to the application on the Voxeo platform. Once the connection is established, the system speaks out the welcome message and goes onward to verify the user by asking for the user email, password and course before the examination can be conducted. The voice application can be accessed using a mobile phone by dialing the iNum

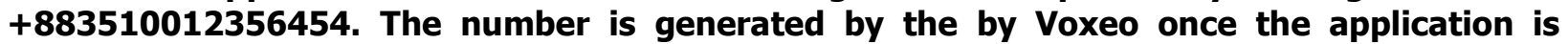
deployed on Voxeo voice server.

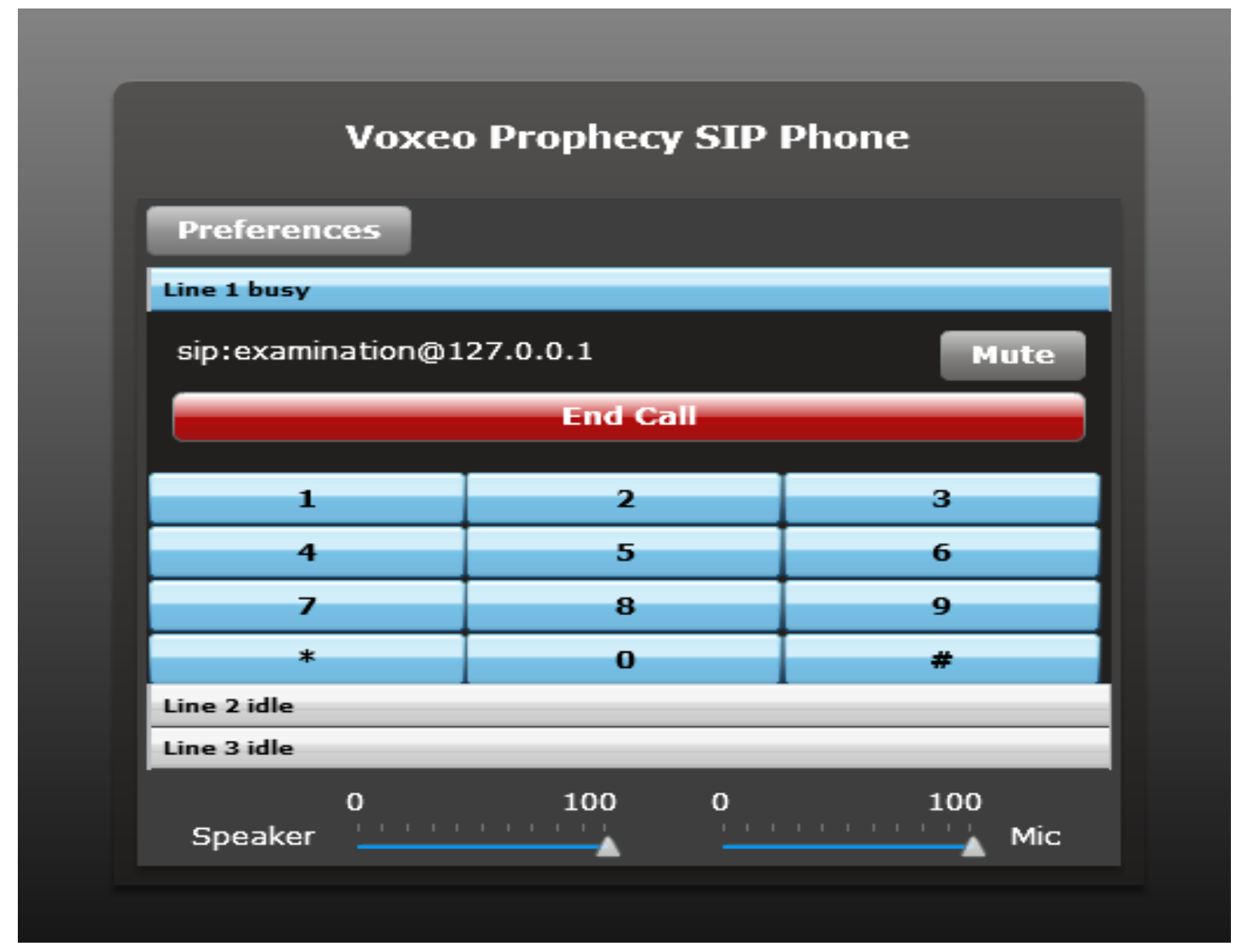

Figure 6. Voxeo Prophecy SIP Phone

\section{Usability evaluation}

The total score of all the respondents was calculated for each of the usability features by finding the mean of all the scores on the survey questionnaires that was administered. The average, standard deviation and variance of all the results collected for the usability features are presented in Table 1. From Table 1, the average user satisfaction was given as 3.33, efficiency as 3.80 and the effectiveness as 3.25. Question 3 had a lower score of 2.4 in that the system was not able to complete most of the user's task and therefore not meeting their needs. However, the users found the system easy to use in Question 11, having a score of 4.2. 
The usability analysis in Figure 7 shows that effectiveness is $31 \%$, efficiency $37 \%$ and users' satisfaction $32 \%$. The results of the usability evaluation showed that the developed application had an 'Average Usability' rating of $\mathbf{3 . 4 8}$ out of 5 scales. A lot of studies on usability evaluation are of the opinion that a system with "Very Bad Usability" should have 1 as mean rating, "2 as Bad Usability", 3 as Average Usability, "4 as Good Usability" and "5 as Excellent Usability". Also, Sauro and Kindlund, (2005), proposed that "Good Usability" and "Average Usability" should have a mean rating of 4 and 3 respectively on a scale of 1-5. Therefore, it can be concluded that the prototype e-examination VUI application developed for the visually impaired learners in ODL has "Average Usability" based on the average (AVG) total rating of 3.48

Table 1. Survey Results

\begin{tabular}{|c|c|c|c|c|}
\hline & ITEMS & AVERAGE & $\begin{array}{l}\text { STARDARD } \\
\text { DEVIATION }\end{array}$ & VARIANCE \\
\hline $\mathbf{S} / \mathbf{N}$ & USER SATISFACTION & & & \\
\hline 1 & $\begin{array}{l}\text { I was able to complete my task } \\
\text { successfully and with ease. }\end{array}$ & 3.2 & 1.03 & 1.07 \\
\hline 2 & $\begin{array}{l}\text { The system worked the way I } \\
\text { expected in the conversation. }\end{array}$ & 3.2 & 1.03 & 1.07 \\
\hline 3 & $\begin{array}{l}\text { The system was able to meet my } \\
\text { need. }\end{array}$ & 2.4 & 0.69 & 0.49 \\
\hline 4 & $\begin{array}{l}\text { I was able to complete my task on } \\
\text { time. } \\
\text { There was no difficult step(s) }\end{array}$ & 3.2 & 1.03 & 1.07 \\
\hline 5 & $\begin{array}{l}\text { involved in the completion of my } \\
\text { task. }\end{array}$ & 3.8 & 0.63 & 0.40 \\
\hline 6 & $\begin{array}{l}\text { The system responded in a friendly } \\
\text { manner (user friendly). } \\
\text { Average } \\
\text { EFFICIENCY }\end{array}$ & $\begin{array}{c}4.2 \\
3.33\end{array}$ & $\begin{array}{l}0.91 \\
0.89\end{array}$ & $\begin{array}{l}0.84 \\
0.82\end{array}$ \\
\hline 7 & $\begin{array}{l}\text { The system was able to understand } \\
\text { what I said. } \\
\text { The pace of interaction with the }\end{array}$ & 3.5 & 0.85 & 0.72 \\
\hline 8 & $\begin{array}{l}\text { system was appropriate in the } \\
\text { dialogue. }\end{array}$ & 3.8 & 1.03 & 1.07 \\
\hline 9 & $\begin{array}{l}\text { I was able to navigate the system } \\
\text { using the dialogue menus. }\end{array}$ & 4.0 & 0.67 & 0.44 \\
\hline 10 & $\begin{array}{l}\text { The system was not sluggish and } \\
\text { slow to reply to me }\end{array}$ & 3.5 & 1.35 & 1.83 \\
\hline 11 & $\begin{array}{l}\text { The system was easy to use. } \\
\text { Average } \\
\text { EFFECTIVENESS }\end{array}$ & $\begin{array}{c}4.2 \\
3.80\end{array}$ & $\begin{array}{l}0.12 \\
0.86\end{array}$ & $\begin{array}{l}0.18 \\
0.85\end{array}$ \\
\hline 12 & $\begin{array}{l}\text { The system did not show any error } \\
\text { message while using it. }\end{array}$ & 2.9 & 0.99 & 0.99 \\
\hline 13 & $\begin{array}{l}\text { The system was able to recover from } \\
\text { any error or mistake easily. }\end{array}$ & 4.0 & 1.15 & 1.33 \\
\hline 14 & $\begin{array}{l}\text { The voice response from the system } \\
\text { was audible and clear. } \\
\text { I was able to familiarize myself with } \\
\text { the system when I used it for the }\end{array}$ & 3.9 & 0.73 & 0.54 \\
\hline 16 & $\begin{array}{l}\text { first time. } \\
\text { I would use the system regularly to } \\
\text { execute my task. }\end{array}$ & 3.2 & 1.31 & 1.73 \\
\hline 17 & $\begin{array}{l}\text { The performance of the system was } \\
\text { satisfactory. } \\
\text { Average } \\
\text { Overall Average rating }\end{array}$ & $\begin{array}{l}3.2 \\
3.25 \\
3.48\end{array}$ & $\begin{array}{l}1.23 \\
1.04 \\
0.93\end{array}$ & $\begin{array}{l}1.51 \\
1.13 \\
0.93\end{array}$ \\
\hline
\end{tabular}




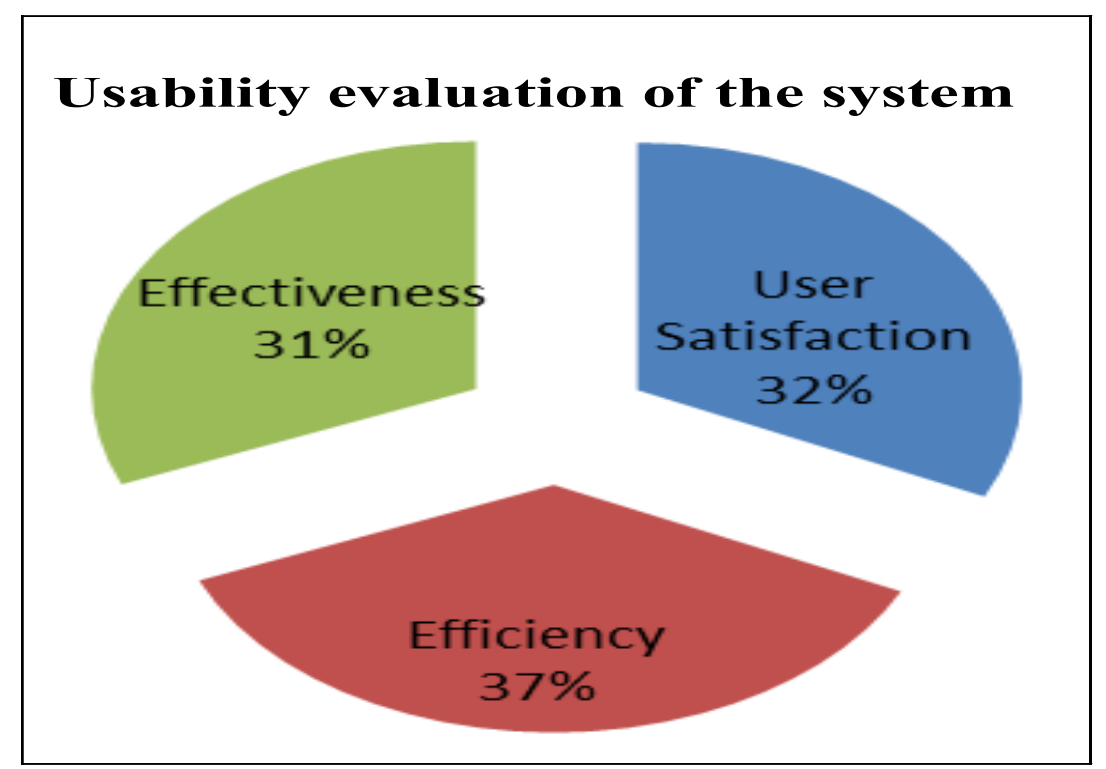

Figure 7. Usability Analysis. Mean=3.48

\section{CONCLUSION}

It should be noted that studies by previous scholars on assistive technology (such as the one reported in this article) for the visually impaired learners, have largely focused on the success stories in developed countries in the Western Europe and North America, where significant progress has been recorded (Ahmad, 2015; Ake, Nena and L. Hannu, 2010 and Ferguson, 2008). However, the status of assistive technology in the developing countries in Africa, Eastern Europe and Asia, mainly highlights drawbacks in its implementation (Charema, 2007). Among the predominant obstacles to the successful implementation of voice-based inclusive education for the visually impaired includes inadequate funding, insufficient trained teachers and support staff, governmental support, ineffective policies and legislation, political instability, and economic crisis (Ahmad, 2015). These are some of the limitations of the study that would need to be addressed, for successful deployment of the voice-based e-examination expert system for the visually impaired. In terms of security of the application, authentication of the caller using email and pin was engaged. Further works on this study will include a third mode of authentication using caller's voice print.

In this paper, an e-examination of voice-based framework for the visually impaired learners in ODL has been provided. The framework was used as a guide to develop a voice-based application as proof of concept. Other tools that aided the implementation include system design, pseudocode, dialogue sequence and algorithm. A usability evaluation of the system was also conducted. The voice-based e-examination system would improve the accessibility of examination in distance learning for learners with visual impairment, as well as other ablebodied learners.

ACKNOWLEDGEMENT: The authors would like to thank Covenant University Nigeria for providing the platform to carry out this research. 


\title{
BIODATA and CONTACT ADDRESSES of AUTHORS
}

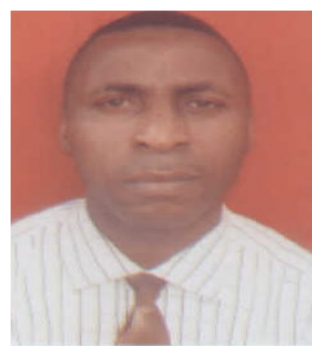

Dr. Ambrose Agbon AZETA is a Senior Lecturer in the Department of Computer and Information Sciences, Covenant University, Ota, Ogun State, Nigeria. He holds B.Sc, M.Sc and Ph.D in Computer Science from University of Benin, University of Lagos and Covenant University Nigeria respectively. He has worked and held several Information Technology (IT) positions in the industry before joining academics in 2005 . His current research interests are in the following areas: Technology-Enhanced Learning, Dialogue Systems (Voice-Enabled Systems), Web/Mobile Computing and Software Engineering. He is a member of the Nigerian Computer Society (NCS) and Computer Professional Registration Council of Nigeria (CPN).

Ambrose Agbon AZETA

Department of Computer and Information Sciences

Covenant University, Ota Ogun State, NIGERIA

Phone: +234 8039540844

Email: ambrose.azeta@covenantuniversity.edu.ng

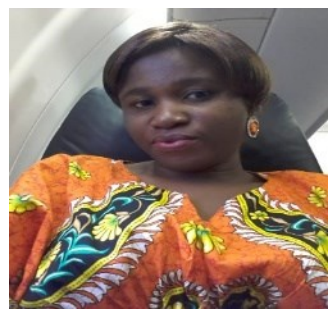

Itorobong A. INAM has completed her master's degree program in Computer Science at Covenant University. Her research interest includes e- Learning technology and Voice-enabling systems.

Itorobong A. INAM

Department of Computer and Information Sciences

Covenant University, Ota, Ogun State, Nigeria.

Phone: +2347082658345

Email: praizinam@gmail.com

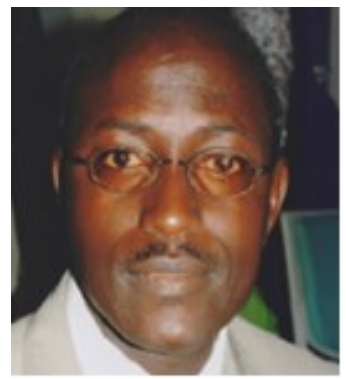

Dr. Olawande DARAMOLA has a doctoral degree in Computer Science with many years of university teaching and research experience. He is currently an Associate Professor of Information Technology at the Cape Peninsula University Technology, Cape Town, South Africa. His research interests include Applied Software Engineering, Intelligent Systems, and Semantic Web Technologies. He has published many academic papers in leading journals and peer-reviewed conferences in the fields of Computer Science, and Information and Communication Technology.

\author{
Olawande DARAMOLA \\ Department of Information Technology \\ Faculty of Informatics and Design \\ Cape Peninsula University of Technology, 800, \\ Cape Town, South Africa \\ Phone: +27618618287 \\ Email: daramolaj@cput.ac.za
}




\section{REFERENCES}

Ahmad, F. K. (2015). Use of Assistive Technology in Inclusive Education. Transcience, Vol. 6, Issue 2, ISSN 2191.

Ake, G., Nena, L. and Hannu, L. (2010). Effective Use of Assistive Technologies for Inclusive Education in Developing Countries: Issues and challenges from two case studies. International Journal of Education and Development using Information and Communication Technology (IJEDICT), 2010, Vol. 6, Issue 4, pp.5-26.

Alsobhi, A. A., Khan, N. and Rahanu, H. (2015). DAEL Framework: A New Adaptive E-learning Framework for Students with Dyslexia. Elsevier ICCS 2015 International Conference on Computational Science, Vol. 51, pp. 1947-1956.

Arditi, A. (2012). Designing for people with partial sight. Retrieved from http: / / www.lighthouse.org

Ayo, C. K., Odukoya, J. A. and Azeta, A. A. (2014). A Review of Open and Distance Education and Human Development in Nigeria. International Journal of Emerging Technologies in Learning, 9(6): 63-67

Azeta, A. A., Ayo, C. K., Atayero, A. A. and Ikhu-Omoregbe, N. A. (2008). Development of a Telephone-based e-Learning Portal. $1^{\text {st }}$ International Conference on Mobile Computing, Wireless Communication, e-Health, M-Health and TeleMedicine (FICMWiComTelHealth '08), $18^{\text {th }}-20^{\text {th }}$ Nov. 2008 at Ladoke Akintola University of Technology (LAUTECH), Ogbomosho, Oyo State, Nigeria, pp. 141-149.

Azeta, A. A., Ayo, C. K., Atayero, A. A. and Ikhu-Omoregbe, N. A. (2009). A Case-Based Reasoning Approach for Speech-Enabled e-Learning System. 2nd IEEE International Conference on Adaptive Science \& Technology (ICAST). December 14 - 16, 2009, Ghana.

Charema, J. (2007). From Special Schools to Inclusive Education: The way forward for Developing Countries South of the Sahara. The Journal of the International Association of Special Education, Vol. 8, No. 1, pp. 88-97.

Choudhury, R. D., Borbora, K. A. and Sarma, S. K. (2013). ESOA: A Web-Based Expert System for Online Assessment: Prototype, Design and Implementation. International Journal of Computer Science Engineering and Information Technology Research (IJCSEITR), Vol. 3, Issue 2, ISSN 2249-6831.

Ferguson, D. L. (2008). International trends in inclusive education: The Continuing Challenge to Teach Each one and Everyone. European Journal of Special Needs Education, Vol. 23, No. 2, pp. 109-120.

Gallivan, P., Hong, Q., Jordan, L. and Li, E. (2002). VoiceXML Absentee System. Proceedings of Mid-Atlantic Student Workshop on Programming Languages and Systems, Pace University, April 19, 2002.

García, V. M. A., Ruiz, M. D. P. and Pérez, J. R. P. (2012). Voice Interactive Classroom, a Service-oriented Software Architecture for Speech-enabled Learning. Journal of Network and Computer Applications, 33(5), 603-610

Hatzilygeroudis, I., Chountis, P., Giannoulis, C. and Koutsojannis, C. (2005). Using Expert Systems Technology For Student Evaluation In A Web Based Educational System. Conference Proceedings from Web-Based Education (WBE 2005). Grindelwald, Switzerland. February 21 - 23, 2005. 
ISO 9241-11 (1998). Ergonomic requirements for office work with visual display terminals (VDTs) - Part 11: Guidance on usability.

Liakou, M. and Manousou, E. (2015). Distance Education for People with Visual Impairments. European Journal of Open, Distance and e-learning, Vol. 18, No. 1, pp. 72-84. ISSN: 1027-5207

Lucic, B., Ostrogonac, S., Sedlar, N. V. and Selujski, M. (2015). Educational Applications for Blind and Partially Sighted Pupils Based on Speech Technologies for Serbian. Hindawi Publishing Corporation. The Scientific World Journal.

Martyn, C. (2014). Meeting the needs of Disabled Students in Online Distance Education - an Institutional case study from The Open University, UK. Distance Education in China, Vol. 12, pp. 18-27.

Motiwalla, L. F. and Qin, J. (2007). Enhancing Mobile Learning Using Speech Recognition Technologies: A Case Study. Eighth World Congress on the Management of eBusiness (WCMeB), Vol. 11, Issue 13, pp. $18-18$

Motiwalla, L. F. (2009). A Voice-enabled Interactive Services (VOIS) Architecture for eLearning. International Journal on Advances in Life Sciences (IJALS), Vol. 1, No. 4, pp. 122-133.

Murphy, E., Kuber, R., McAllister, G., Strain, P. and Yu, W. (2008). An empirical investigation into the difficulties experienced by visually impaired Internet users. Universal Access in the Information Society, Vol. 7.

NCES (2016). National Center for Education Statistics (NCES) Academic Library Survey.

Olu, A. A. (2012). A Simulated Enhancement of Fisher-Yates Algorithm for Shuffling in Virtual Card Games using Domain-Specific Data Structures. International Journal of Computer Applications, Vol. 54, No.11, ISSN 0975 - 8887.

Papadopoulos, K., Simaioforidis, Z., Charitakis, K and Barouti, M. (2014). University Examination System for Students with Visual Impairments. ICCHP, 2014, Part 11, LNCS 8548, pp. 358-365. Springer Publishing.

Puzis, Y., Borodin, Y., Puzis, R. and Ramakrisnan, I.V. (2013). Predictive Web Automation Assistant for People with Vision Impairments. International World Wide Web Conference Committee (IW3C2). WWW 2013, May 13-17, 2013, Rio de Janeiro, Brazil.

Raghuraman, M. B. (2004). Design and Implementation of V-HELP System - A Voice-enabled Web Application for the Visually Impaired. A Master's project presented to the Faculty of the Graduate College in the University of Nebraska in partial fulfillment of requirements for the degree of Master of Science. Major: Computer Science. 2004.

Sauro, J. and Kindlund, E. (2005). A Method to Standardize Usability Metrics into a Single Score. In Proceedings of the SIGCHI conference on Human factors in computing systems, 2005, pp. 401-409. ACM.

Velonis, A., Milonas, T., Papazidis, G. and Dimitriou, G. (2009). VoiceCampus: An Automated Interactive Voice Response for Students.

Voxeo Prophecy (2003). The Voxeo Prophecy Platform. Available online at: www.voxeo.com/prophecy.

Willings, C. (2016). Teaching Students with Visual Impairments. Retrieved from http://www.teachingvisuallyimpaired.com 